\title{
Neighborhood satisfaction and use patterns in urban public outdoor spaces: Multidimensionality and two-way relationships
}

\author{
SARA HADAVI* \\ University of Michigan, School of Natural Resources and Environment \\ sahadavi@umich.edu \\ Tel.: +1 7348461037 \\ Dana Building, 440 Church Street, Ann Arbor, MI 48109-1041, USA \\ RACHEL KAPLAN \\ University of Michigan, School of Natural Resources and Environment \\ rkaplan@umich.edu \\ *orresponding author
}




\begin{abstract}
Neighborhood satisfaction and use patterns in public outdoor spaces are generally viewed as single entities, ignoring their multidimensionality as well as detailed associations between them. Such a general assessment raises questions of the kinds of neighborhood characteristics that accrue to satisfaction, and the variety of environmental affordances perceived by residents with respect to nearby outdoor settings. Given the significant role of these factors in people's life satisfaction and wellbeing, a nuanced approach is needed to help us better understand people-environment relationships and examine practical solutions for creating more livable neighborhoods. This study investigated two-way associations between four aspects of neighborhood satisfaction and three forms of use, as well as the role played by perceived barriers to neighborhood use in these associations. A random sample of 434 Chicago residents participated in a survey (mailed and on-site) with a five-point rating scale. The three major findings through generalized linear modeling include; 1) multidimensionality of both neighborhood satisfaction and use patterns as important to consider in people-environment studies, 2) the significant roles as predictors and as outcomes played by both neighborhood satisfaction and use patterns, with only one factor from each set showing a two-way relationship, and 3) the main effect of perceived barriers on three of the neighborhood satisfactions, and their interactive effect with several of the use pattern and satisfaction factors. These findings contribute to our understanding of people-environment relationships in urban public spaces and provide insights for improving neighborhood satisfaction and frequency of use of public outdoor spaces.
\end{abstract}

Keywords: Chicago, interaction analysis, people-environment relationship, perceived barriers, residential, urban outdoors. 


\section{Introduction}

To what extent does a person's use of their nearby outdoor space affect their satisfaction

3 with their neighborhood environment? Alternatively, to what extent does satisfaction with one's

4 neighborhood impact how one uses it? Studies have examined these questions separately, and

5 have provided findings that support both perspectives. Much of that literature, however,

6 overlooks the multidimensionality of the constructs use and neighborhood satisfaction. It is also

7 not clear how perceived barriers to use affect the associations between neighborhood satisfaction

8 and use in urban residential areas. Given the significant role these factors play in people's life

9 satisfaction and wellbeing (e.g., Fernandez and Kulik, 1981; Kaplan and Kaplan, 1989; Kweon et

10 al., 2010; Ward Thompson and Aspinall, 2011), it is worth investigating multiple aspects of

11 satisfaction and use in detail. This study investigated different aspects of satisfaction with

12 neighborhood outdoor settings, various types of use of such spaces, and the possible associations

13 between these aspects in urban residential neighborhoods while controlling for perceived barriers

14 to neighborhood use.

\section{$15 \quad$ What does it mean to be satisfied with a neighborhood?}

16 Research on neighborhood satisfaction has separately investigated a relatively wide range of

17 contributing factors including socio-demographics (Sallis et al., 2009; Kweon et al., 2010),

18 housing ownership (Basolo and Strong, 2002; Rohe, Van Zandt, and McCarthy, 2013), safety

19 (Cook, 1988; Burby and Rohe, 1989), and physical attributes of the environment (Kaplan, 2001;

20 Sirgy and Cornwell, 2002; Lee et al., 2008; Hur, Nasar, and Chun, 2010; Kweon et al., 2010; 
21 Hur and Nasar, 2014). While providing valuable findings, most of these studies have examined

22 neighborhood satisfaction as a single entity such as overall satisfaction (e.g., Galster and Hesser,

23 1981; Hur, Nasar and Chun, 2010; de Jong et al., 2012). Such a general assessment raises

24 questions of the kinds of neighborhood characteristics that accrue to satisfaction. For instance, is

25 it satisfaction with the appearance of a neighborhood or the quality of public spaces that plays an

26 important role? Does the amount of available green features or the activities afforded by the

27 outdoor settings share in people's perception of neighborhood satisfaction? Disregarding the

28 multidimensionality of neighborhood satisfaction leaves such questions unanswered. One of the

29 risks of not knowing the answers to these questions would be inability to create or redevelop

30 neighborhood spaces that are responsive to users' perception. This may lead to formation of

31 outdoor spaces that do not meet residents' needs and preferences. Some studies have focused on

32 specific aspects of satisfaction such as neighborhood appearance and attractiveness (Gruber and

33 Shelton, 1987; Parkes, Kearns, and Atkinson, 2002) and neighborhood safety (Cook, 1988;

34 Lovejoy, Handy, and Mokhtarian, 2010). While previous research has demonstrated the

35 multidimensionality of residential satisfaction (Amerigo and Aragones, 1997; Francescato,

36 2002), only a few studies have put multidimensionality of satisfaction as the center of

37 investigation (e.g., Bonaiuto et al., 1999; Adriaanse, 2007; Fornara, Bonaiuto, and Bonnes,

38 2010). Further, few studies can be found on multiple dimensions of neighborhood satisfaction in

39 association with different types of outdoor use. We argue that the complexity of environmental

40 characteristics and people's perception warrant inclusion of a wider range of satisfactions. By

41 investigating multiple aspects of neighborhood satisfaction (satisfaction with quality of public

42 space, amount of green features, amount of affordances and neighborhood comfort), this study

43 offers a richer understanding of people's perception of their physical environment which may

44 have implications for practitioners in improving neighborhood satisfaction in residential areas. 
What is meant by neighborhood use?

While the use of outdoor spaces has been shown to be important with respect to its positive effects on wellbeing (Ellis, Lee, and Kweon, 2006; Ward Thompson, 2011; Ward Thompson and Aspinall, 2011), use is often investigated as a single entity. For instance, use has been investigated in terms of walking in the neighborhood (Ball et al., 2001; Humpel, Marshall, et al., 2004), physical activity (Bjork et al., 2008), park use (Tinsley, Tinsley, and Croskeys, 2002), social activity (Hur and Morrow-Jones, 2008) and community gardening (Kaplan, 2001). However, the complexity of environmental attributes and affordances, as well as people's needs and preferences result in a multifaceted people-environment relationship that comprises a diversity of use patterns. Disregarding the diversity of use patterns in urban residential contexts leaves us with ambiguity that can translate both to ill-allocated financial resources and psychological impacts, resulting in decision-making procedures that may reduce the residents' likelihood of outdoor space use. This study investigated three types of use of outdoor spaces (green/social space use, active engagement with the environment, and walk to non-nature destinations) based on the purpose of being outdoors which can provide insights into ways to encourage people to spend more time outdoors.

\section{The association between neighborhood satisfaction and use patterns}

A few studies have reported an association between neighborhood satisfaction and the ways people use their outdoor spaces (e.g., Kaplan and Kaplan, 1989; Kaplan 2001; Kearney, 2006).

These studies mostly identify use of outdoor spaces as the predictor of satisfaction level (e.g., Kaplan, 2001; Kearney, 2006), meaning that the more people use their nearby outdoor spaces, the more satisfied they are with their neighborhood. However, other findings raise doubts about accepting such a one-way relationship between satisfaction and use. As many studies have 
revealed, people like outdoor settings depending on the extent to which the settings meet their

69 needs (Kaplan and Kaplan, 1982). Having nature nearby can also be a potential response to many

70 basic needs through offering a wide range of affordances to urban residents (Kaplan, Kaplan, and

71 Ryan, 1998) and is thus associated with neighborhood satisfaction and use. It is also plausible to

72 expect that the more people are satisfied with their nearby outdoor spaces, the more likely they

73 are to use them (Duvall, 2013).

Considering the possibility of this two-way association between neighborhood satisfaction

75 and use raises a number of questions: Do all aspects of neighborhood satisfaction and use

76 patterns have two-way associations? If not, what aspects of neighborhood satisfaction might

77 predict what forms of use of outdoor spaces? What forms of use may predict neighborhood

78 satisfaction? Finding answers to such questions gives us a richer understanding of prior

79 environment-behavior studies while also providing insights into ways to both improve

80 neighborhood satisfaction through encouraging specific forms of use, and to increase use of

81 outdoor spaces through improving aspects of neighborhood satisfaction. By contrast, the cost of

82 disregarding these associations in practice may result in investing on outdoor spaces that are

83 underutilized, and having less satisfaction and sense of community in neighborhoods. To help

84 answer some of these questions, this study investigated the possibility of two-way relationships

85 between four dimensions of neighborhood satisfaction and three forms of use patterns.

\section{Perception of barriers to neighborhood use}

While many factors are likely to impact use patterns, particularly salient are residents' perceptions of barriers to use which may affect perceived accessibility, one of the most

89 commonly measured factors across urban neighborhood studies. With respect to public green

90 spaces, physical access is evaluated in terms of the distribution of such spaces and often includes 
91 evaluation of barriers that obstruct access, such as long distances and unsafe routes (Shackleton

92 and Blair, 2013). Perceived barriers that affect neighborhood satisfaction or frequency of use of

93 outdoor spaces include unattractiveness (Giles-Corti et al., 2005), long distances (Giles-Corti et

94 al., 2005; Wright Wendel, Zarger, and Mihelcic, 2012), safety issues (Lee, 1981; Ward

95 Thompson and Aspinall, 2011) and major roads (Giles-Corti et al., 2005). Given the growing

96 evidence of the importance of accessibility and barriers to use of public spaces, this study

97 examined the extent to which perceived barriers affect each component of neighborhood

98 satisfaction and use patterns.

\section{$99 \quad$ Major questions}

This study focuses on two major issues. First, identifying specific and useful components of

101 neighborhood satisfaction, use patterns and barriers to neighborhood use that could be

102 considered as measures for these concepts. Second, examining the relationships among the

103 satisfactions and use patterns while controlling for the potential effect of barriers. Assuming that

104 uses can influence satisfaction, or alternatively, that satisfaction may influence use patterns, and

105 that barriers to neighborhood use may influence both satisfaction and use patterns, it was

106 hypothesized that some dimensions of neighborhood satisfaction and use have two-way

107 relationships, and barriers to neighborhood use play an interacting role between measures of

108 satisfaction and use. 


\section{Methods}

\section{Study area}

112 The study area covers 3,400 acres of a moderately dense residential area in Chicago, IL that

113 includes portions of four community areas: Logan Square, Avondale, Humboldt Park, and West

114 Town (See Fig. 1). Choice of this area was based initially on analysis of citywide GIS modeling

115 considering criteria comprising median income ${ }^{1}$, housing stock type ${ }^{2}$, crime rate, and green

116 spaces $^{3}$. The GIS model characterized the study area by majority of multifamily houses as

117 opposed to single-family houses and high rises (in order to target residents who do not have

118 private backyards and thus primarily rely on public green spaces), low crime rate (in order to

119 avoid the possible negative effects of high crime rate on the residents' use of public spaces), and

120 residents with median incomes between $\$ 25000$ and $\$ 75000$ (in order to target approximately the

121 middle-income class). The exact boundary of the study site was determined based on field

122 investigations, considering availability of a variety of public green spaces including large and

123 small parks, green boulevards, and very small community gardens.

124 The study site is predominantly residential with business/commercial land uses along the

125 major streets. In addition to parks and green spaces shown in Figure 1, there are a number of

126 educational areas (schools) distributed throughout the site, and a few small manufacturing sites

127 in the south west. Adjacent to the study area in the south and west there is part of an industrial

128 corridor as well.

129

[Insert Fig.1] 


\section{$131 \quad$ Research instrument}

132 A survey, using a five-point rating scale was used for assessing a number of issues (Hadavi,

133 2015), including neighborhood satisfaction, use pattern, and barriers to use of outdoor spaces

134 (Table 1). Demographic information was also collected. Both a printed version and a web link 135 were used as formats.

136 Satisfaction with the neighborhood included two questions, one focused on overall

137 satisfaction with the neighborhood and the other one emphasized satisfaction with the amount of 138 specific nature features and spaces in the neighborhood. Three separate questions were included

139 to tap a variety of patterns of outdoor space use, including frequency of walking in the

140 neighborhood for different purposes, frequency of use of specific public green spaces and

141 recreational areas, and frequency of specific outdoor activities in the neighborhood. Survey items 142 also included questions about potential barriers to using outdoor spaces (Table 1).

[Insert Table1]

\section{Sample recruitment and characteristics}

146 The first phase of data collection was conducted through a mail survey. A stratified random 147 sample was drawn based on proximity of the multi-family houses to green spaces including both 148 buildings close to green spaces (50\% within a block) and far from them (50\% more than four

149 blocks). The target population (total of 5309 eligible households) was stratified by nine-digit zip 150 codes to select a random sample of 2500 units. From a randomly selected starting point, 
151 addresses were selected using the mathematically determined interval — the total eligible

152 households (5309) divided by sample size (2500). An initial invitation postcard was sent to the

153 sample indicating that a survey would be coming, followed by the survey a week later. The

154 response rate of the mail survey was very low, 4.9\%, (111 mail returns plus 12 online responses).

155 The second phase of data collection was on-site. We approached individuals in the study

156 area during various summer events such as farmers' market, music festivals, kids' activity tents,

157 and community gatherings, as well as in outdoor spaces of a few coffee shops in the study area.

158 When individuals showed interest in filling out the survey, they were asked to find their home on

159 a simple sketched map to make sure that they were residents of the study area. Two

160 neighborhood organizations, Avondale Neighborhood Association (ANA) and Logan Square

161 Neighborhood Association (LSNA), also agreed to share the online survey link with their

162 members via email. In this phase, the total number of participants who lived in the study area

163 was 311 (264 on-site survey plus 47 online survey participants). The total number of participants

164 was 468 , but data from 34 could not be analyzed due to either incompleteness or because the

165 participant lived outside of the study area. Therefore, the total sample size used in this study was

166434.

167 Nearly 60 percent of the sample population has lived in the neighborhood for more than

168 three years, meaning that the majority of the participants are quite familiar with the

169 neighborhood. A comparison between demographic data from U.S. Census Bureau for Chicago

170 City (2012) and that of the sample population shows that the study sample is generally younger

171 and more educated than Chicago population. Demographic information collected through the

172 survey (Table 2) shows that more than half of the sample population uses public transportation

173 (bus or train) to get to work, which is twice the average for Chicago as a whole. 
[Insert Table 2]

\section{Data analysis}

177 In light of the study's focus on generating resident-based neighborhood satisfaction and use

178 patterns, Exploratory Factor Analysis (EFA) was used (SPSS, version 22) to determine each of

179 the latent variables. Principal Components, with Varimax rotation and a maximum of 25

180 iterations for convergence, was followed for each of the constructs. Only the loadings with

181 absolute values greater than 0.50 were included in the analysis. The larger double loader was

182 selected if it was at least 0.05 greater than the alternative; otherwise the item was eliminated

183 from the final solution. Factor means were calculated and saved as latent variables. Cronbach

184 Alpha was calculated for each factor to test for reliability and only factors with Alpha

185 coefficients greater than .73 were retained. The use of EFA permits examination of categories or

186 patterns as opposed to an emphasis on the magnitude of the ratings of individual items.

187 After defining distinct latent variables, Pearson correlations were used to determine the 188 extent of relationship between the three sets of latent variables -neighborhood satisfaction, use 189 patterns and barriers to neighborhood use. Then in order to assess the influence of each of the

190 satisfaction measures on use patterns as well as the influence of each of the use patterns on 191 satisfaction, two separate analyses were carried out using generalized linear modeling. For each 192 analysis barriers to neighborhood use were included as binary measures (based on the sample 193 means) to examine their potential interactive effect. Despite the correlations between various 
194 measures, Variance Inflation Factor (VIF) assessment showed that multicollinearity was not an

195 issue in this study.

197 Results

198 Neighborhood satisfaction measures

199 Separate exploratory factor analyses (EFA) were conducted for the two neighborhood

200 satisfaction questions (Table 1). As shown in Table 3, each question generated two distinct

201 measures explaining different aspects of neighborhood satisfaction. The first two factors,

202 concerning satisfaction with the quantity of nearby outdoor features, focus on the Amount of

203 Affordances $(\mathrm{Cr} \alpha=0.84)$ and the Amount of Green Features $(\operatorname{Cr} \alpha=0.77)$. The Amount of

204 Affordances reflects the extent to which the participants are satisfied with the amount of public

205 green spaces that are intended for doing meaningful activities such as sitting, picnicking,

206 socializing and playing. By contrast, Amount of Green Features indicates the extent to which the

207 participants are satisfied with the amount of trees, shrubs, flowers and lawns. The third factor,

208 Quality of Public Spaces ( $\mathrm{Cr} \alpha=0.88)$, represents the extent to which the participants are

209 satisfied with their neighborhood in terms of overall appearance, the variety of green spaces and

210 socializing opportunities. The final factor, Neighborhood Comfort $(\mathrm{Cr} \alpha=0.76)$, includes safety

211 issues and peacefulness. The "farmers market" item also emerged as part of this factor although

212 it is more specific than the other items in the factor. Two items, "amount of vegetable gardens"

213 and "street lighting," with loadings <.5 were dropped from further analysis. The item "sense of

214 community" was eliminated because of almost equal loadings on factors 3 and 4. 
The mean values (Table 3) of the satisfaction factors suggest a moderate degree of

216 participants' satisfaction with evaluated aspects of neighborhoods, with considerable variation

217 among the items. Based on the factor means, participants are far more satisfied with the amount

218 of green features (3.75) than with the quality of the public spaces (3.20). Satisfaction with the

219 amount of sitting areas rated lowest (2.93) among the examined affordances. While the mean for

220 Satisfaction with Neighborhood Comfort is relatively high (3.51), it would have been lower

221 without the "Farmers market" item (mean 3.87). As would be expected nighttime safety is

222 perceived far lower (2.97) than daytime safety which was rated positively (4.09).

[Insert Table 3]

225 Neighborhood use pattern measures

226 Three distinct use pattern measures emerged from the EFA (Table 4). Three items -

227 "running," "biking," and "dog walking" - had loadings lower than the 0.5 criterion and were

228 eliminated from further analysis. The first factor, Green/Social Space Use, with alpha coefficient

229 of 0.91 , incorporates a variety of passive uses of green outdoor spaces such as resting,

230 picnicking, sitting and watching as well as specific nature-based destinations such as boulevards

231 or parks. The mean for this measure is at mid-scale, but some of the item means such as

232 picnicking (2.23) and use of boulevard sitting areas (2.66) are less than mid-scale, while

233 "walking for pleasure" and "parks with large trees" have means above 3.5. 
The four items of the Active Engagement measure $(\mathrm{Cr} \alpha=.76)$, include community gardens,

235 play areas for younger children, and sports. The low mean (1.87) for this measure suggests that

236 most participants only participate in these activities "a little."

237 The five items comprising the final measure $(\mathrm{Cr} \alpha=.76)$ all entail non-nature based reasons

238 for walking and thus are designated as Walk to Non-nature Destinations. The mean, 3.92,

239 indicates participants walk in the neighborhood "quite a bit" to run errands and reach needed

240 destinations.

\section{Barriers to neighborhood use}

242 Two distinct factors for barriers to neighborhood use emerged through EFA (Table 5). The

243 first factor, named Various Perceived Barriers $(\mathrm{Cr} \alpha=0.85)$, included physical attributes of the

244 neighborhood such as fences, unpleasant appearance and lack of walkability, as well as

245 individual feelings about the neighborhood such as lack of information, safety and sense of

246 community. By contrast, the second factor, Transportation Barriers $(\mathrm{Cr} \alpha=.81)$ included "major

247 roads", "traffic" and "distance". The low means for both barrier factors (2.09 and 2.34,

248 respectively), indicate that, on average, the participants consider the barriers to use of the

249 outdoor spaces of relatively lower significance in the study area. However, it is still important to

250 explore how these perceived barriers are associated with neighborhood satisfaction and use.

[Insert Table 4]

[Insert Table 5] 


\section{Associations between neighborhood satisfaction, use pattern, and barrier measures}

255 Pearson's correlation analysis (Table 6) shows that several of the satisfaction measures have

256 relatively high interrelations and one of the use patterns is correlated $(r>.40)$ with the other two.

257 However, as shown in the highlighted area of Table 6, only one of the 12 correlations between

258 any of the satisfaction and use pattern factors is greater than .40, which is related to Satisfaction

259 with Quality of Public Spaces and Green/Social Space Use. The table also shows that Various

260 Perceived Barriers have significant negative correlations with all satisfaction and use measures

261 except for Active Engagement with the environment. While Transportation Barriers have

262 significant negative correlations with all neighborhood satisfaction measures, they show

263 significant negative correlation only with Green/Social Space Use.

[Insert Table 6]

Neighborhood satisfaction as predictor of use pattern

The first generalized linear model examined the four neighborhood satisfaction factors as

268 predictors of each of the three use patterns, adjusted for barriers to neighborhood use, to explore

269 both main effects of satisfaction and potential interaction effects with barriers. The results of

270 these analyses are presented in Table 7, with a separate row for each of the use patterns.

271 Main effects. Among the four satisfaction factors only Satisfaction with Quality of Public

272 Space has significant main effects on use patterns. Specifically, this factor has the strongest main 
273 effect on Green/Social Space Use $(\beta=.63)$, and its main effects on the other two forms of use,

274 Active Engagement ( $\beta=.39)$ and Walk to Non-nature Destinations $(\beta=.32)$ are substantially

275 lower. There were no main effects related to perceived barriers to use.

276 Interaction effects. While satisfaction with Amount of Green Features and Neighborhood

277 Comfort do not show main effects on use patterns, as shown in Table 7, Various Perceived

278 Barriers interact with satisfaction with Amount of Green Features to predict Green/Social Space

279 Use $(\beta=-.19, \mathrm{p}<.05)$, and also interact with Neighborhood Comfort to predict the frequency of

280 Walking to Non-nature Destinations $(\beta=.38, \mathrm{p}<.005)$. This form of use is also affected by the

281 interaction effects of Transportation Barriers and satisfaction with Amount of Green Features

$282(\beta=.21, \mathrm{p}<.05)$. These results show that with respect to Walking to Non-nature Destinations, both

283 the perception of barriers and two of the satisfaction components have an interactive role.

284 Furthermore, the effect of satisfaction with Amount of Green Features on the Use of

285 Green/Social Space is moderated by the perception of Various Barriers.

Use pattern as predictor of neighborhood satisfaction

The second generalized linear model explored the effects of use patterns and their

288 interaction effects with barriers on each of the four satisfaction factors. Both main effects of the

289 predictors and the interaction effects of barriers were investigated, and the results are

290 summarized in Table 8.

291 Main effects. Green/Social Space Use shows significant main effects on each of the four

292 measures of neighborhood satisfaction. The main effects on satisfaction with Amount of

293 Affordances ( $\beta=.66)$ and Quality of Public Space $(\beta=.72)$ are higher than, and almost twice as

294 great as the effects on satisfaction with Amount of Green Features ( $\beta=.33)$ and Neighborhood 
295 Comfort ( $\beta=.37)$. By contrast, Active Engagement has main effects only on satisfaction with 296 Amount of Affordances ( $\beta=-.27, \mathrm{p}<.05)$. It should be noted that in this analysis, high-barrier is 297 considered as the reference category, and there is a negative association between Active 298 Engagement and satisfaction with Amount of Affordances.

299 While the first model showed that perceived barriers do not have main effects on use 300 patterns, the second model demonstrates main effects of Various Perceived Barriers on three 301 satisfaction measures, satisfaction with Amount of Affordances $(\beta=1.65, \mathrm{p}<.005)$, Amount of 302 Green Features $(\beta=1.43, \mathrm{p}<.01)$ and Quality of Public Space $(\beta=.88, \mathrm{p}<.05)$. Interaction effects. While Various Perceived Barriers do not have main effects on

304 Neighborhood Comfort, they interact with two forms of use - Green/Social Space Use and Walk 305 to Non-nature Destinations - to predict this satisfaction measure ( $\beta=-.23$ and .32 , respectively). 306 Also, Transportation Barriers have interaction effects on the relationship between Walk to Non307 nature Destination and satisfaction with Amount of Green Features in the neighborhood. In other 308 words, the effect of walking to non-nature destinations in the neighborhood on satisfaction with 309 amount of green is moderated by perceived transportation barriers, while the effects of the 310 frequency of use of green/social spaces and walking to non-nature destinations on neighborhood 311 comfort depend on people's perception of those barriers that are not related to transportation.

\section{[Insert Table 7]}

[Insert Table 8] 
316 The results are summarized in Figs. 2 and 3 and in the bullet points below.

317 - Use and satisfaction show different patterns of results when each is considered as an $318 \quad$ outcome variable.

319 - When a multiplicity of dimensions of neighborhood satisfaction and forms of use is 320 considered, many of these elements play a significant role in the association with other $321 \quad$ measures.

322 - Among the four satisfaction measures and three use measures, there was only one 323 significant two-way relationship, namely between satisfaction with Quality of Public 324 Space and Green/Social Space Use (Fig. 2).

325 - Barriers to neighborhood use have a main effect in predicting neighborhood satisfaction 326 but not neighborhood use.

327 - As shown in Fig. 3, two of the satisfaction measures and two of the use patterns are 328 included in an interactive cyclic relationship that relates to the two measures of barriers to neighborhood use.

[Insert Fig. 2] 


\section{Discussion and conclusion}

334

335

336

337

338

339

340

In this study we focused on the significance of considering the multidimensionality of both neighborhood satisfaction and use patterns in environment-behavior studies and the necessity of investigating the possible two-way relationships between multiple aspects of neighborhood satisfaction and use in urban residential areas. As discussed earlier these issues can have important practical consequences for creating or redeveloping outdoor spaces that are more favored and more frequently used, resulting in investment on outdoor spaces that address residents' neighborhood satisfaction.

This study examined the associations between four aspects of neighborhood satisfaction and three forms of use and the interacting role of barriers to neighborhood use in a residential area in Chicago based on the data collected from 434 survey participants. There were three major findings; 1) multidimensionality of both neighborhood satisfaction and use patterns as important to consider in environment-behavior studies, 2) the significant roles as predictors and as outcomes played by both neighborhood satisfaction and use patterns, with only one factor from each set showing a two-way relationship (Fig. 2), and 3) the main effect of perceived barriers on three dimensions of the neighborhood satisfaction, and their interactive effect with several of the use pattern and satisfaction factors. These findings contribute to our understanding of peopleenvironment relationships in urban public spaces and provide insights into how to improve neighborhood satisfaction and frequency of use of outdoor spaces.

\section{Multi-dimensionality of neighborhood satisfaction and use}

Investigating the participants' perceptions about both the amount and the quality of outdoor green spaces, and their satisfaction in a more detailed manner in this study allows us to decipher 
more about their satisfaction and needs in terms of multiple attributes and affordances of a

356 complex environment. Two of these data-driven measures are directly related to the nature

357 component of outdoor spaces, and the other two address the activities afforded by outdoor spaces

358 and the degree of perceived safety and peacefulness in the neighborhood.

359 Instead of investigating neighborhood satisfaction as a single entity or focusing on one

360 specific aspect of it as is the pattern in many studies (e.g. Galster and Hesser, 1981; Gruber and

361 Shelton, 1987; Parkes, Kearns, and Atkinson, 2002; Hur, Nasar and Chun, 2010; de Jong et al.,

362 2012), this study examined how people perceive and appreciate urban outdoor spaces in a more

363 inclusive way. The findings demonstrate that different aspects of neighborhood satisfaction

364 behave differently in relation with forms of use of outdoor spaces, highlighting the necessity of

365 considering the multi-dimensionality of neighborhood satisfaction in environment-behavior

366 studies.

In terms of patterns of use, the scope of this work goes beyond the consideration of a single

368 entity such as walking in the neighborhood, park use, physical activity or gardening that have

369 been separately investigated in previous studies (Kaplan, 2001; Tinsley, Tinsley, and Croskeys,

370 2002; Humpel, Marshall, et al., 2004). By investigating three forms of use (frequency of use of

371 green/social spaces, active engagement with the environment such as playing or gardening, and

372 walking in the neighborhood for non-nature purposes) the results show important differences in

373 their roles with respect to multiple aspects of people's satisfaction with the environment as well

374 as barriers to use. The findings thus indicate that examination of neighborhood satisfaction and

375 use as single entities may be shortsighted given their differential roles in association with other

376 aspects and perceived barriers to neighborhood use. 
In answer to the question regarding the extent to which neighborhood use predicts satisfaction or satisfaction predicts use, this study found that these two factors reinforce each other. While confirming previous findings, in terms of the general effects of use of outdoor spaces on neighborhood satisfaction (e.g., Kaplan, 2001; Kearney, 2006), this study showed that

382 satisfaction with quality of public space and frequency of use of green and social spaces are

383 highly interrelated and have a two-way relationship (Fig. 2). More specifically, the more the

384 residents are satisfied with the overall appearance of the neighborhood, the variety of green

385 spaces, the amount of open space, and the opportunities for socializing, the more likely they are to use their nearby green/social spaces and walk for pleasure in the neighborhood, and vice versa. Acknowledging that this relationship with respect to nearby nature holds in both directions is helpful in terms of understanding the multi-dimensional effects of physical attributes of the environment on both neighborhood satisfaction and use patterns. It sheds light on ways to improve satisfaction and frequency of use in public outdoor spaces through identifying important

391 attributes of the environment and improving them.

393 predicting all neighborhood use patterns investigated in this study; the more the residents are

394 satisfied with the quality of public space, the more likely they are to spend time outdoors for

395 many different purposes including walking either for pleasure or to reach a destination,

396 socializing and even getting actively involved with the environment through playing games or

397 gardening. This pattern of associations, however, was not found with respect to other aspects of

398 neighborhood satisfaction. Even when the participants are satisfied with the potential amount of

399 outdoor activities, amount of green features or the level of peacefulness and safety in the 
400 neighborhood, they may resist using outdoor spaces if they perceive that there are barriers to

401 neighborhood use.

402 By contrast, the use of green/social spaces may increase the level of different sources of 403 neighborhood satisfaction. However, the impact of use on satisfactions is specific to the kind of 404 use; more frequent walks to non-nature destinations or use of active recreation areas do not result 405 in higher level of neighborhood satisfaction. These findings carry a practical message; in order to 406 increase use and walking frequency in residential neighborhoods we need to increase the quality

407 of public spaces through improving overall appearance of the neighborhood, amount and variety

408 of green spaces and provide more opportunities for outdoor community gatherings and

409 socializing. As the results show, improving the quality of public space is more likely to

410 encourage more frequent use of green/social spaces that can lead to improving other aspects of

411 neighborhood satisfaction. This is particularly important because a growing body of research has

412 revealed the associations between neighborhood satisfaction and use and mental wellbeing in

413 urban areas (Kaplan and Kaplan, 1989; Grahn and Stigsdotter, 2003; Ward Thompson and

414 Aspinall, 2011).

\section{Barriers to neighborhood use}

416 While confirming the negative association between barriers and both neighborhood 417 satisfaction and use patterns, this study also resulted in some findings that are not in line with the 418 previous literature.

419 This study found that various perceived barriers including unpleasant open spaces, low 420 maintenance, and lack of walkable sidewalks, sense of community and safety have significant 421 main effects on three aspects of satisfaction including satisfaction with quality of public space 
422 and amounts of both affordances and green elements in the neighborhood. Despite the

423 multifaceted nature of barriers and satisfaction measures investigated in this study, it is safe to

424 consider that these findings are consistent with the literature in terms of the negative effects of

425 barriers such as unpleasantness (Parkes, Kearns, and Atkinson, 2002), safety concerns (Lee,

426 1981; Cook, 1988) and low maintenance (Hur and Nasar, 2014) on neighborhood satisfaction.

427 Furthermore, Amberger and Eder's (2012) finding that perception of favored nearby outdoor

428 green spaces is positively related to sense of community, offers a partial explanation for our

429 finding of lack of sense of community as a barrier to neighborhood use being negatively

430 associated with aspects of neighborhood satisfaction.

431 The discrepancies from the literature are related to the association between barriers and use

432 patterns. As documented previously, the frequency of use of outdoor spaces is negatively

433 influenced by many barriers such as unpleasant appearance of the neighborhoods (Giles-Corti et

434 al., 2005), safety issues (Ward Thompson and Aspinall, 2011) and long distances (Wright

435 Wendel, Zarger, and Mihelcic, 2012). This study, however, does not show main effects of

436 perceived barriers on use patterns. Given the strong associations between aspects of satisfaction

437 and use, it is plausible to consider that barriers have influence on use patterns through their

438 effects on satisfation. Moreover, the lack of main effects of transportation barriers on either

439 satisfaction or use patterns is a further discrepancy from the literature. As shown in Fig. 3, our

440 results point to a complex interactive role that both transportation and various perceived barriers

441 play with respect to two of the satisfaction measures and two of the use patterns.

442 These findings suggest that in urban neighborhood studies it is essential to consider the

443 significant complex role of both transportation and non-transportation barriers in understanding

444 the associations between various aspects of neighborhood satisfaction and use. The complexity 
445 of the relationships shown in Fig. 3 reminds us of the significance of multidimansionality of

446 satisfaction and use and their strong interrelations while controlling for barriers. By highlighting

447 the significant interacting role of barriers, it also illuminates that investigation of neighborhood

448 satisfaction without considering its interrelations with use patterns and barriers may be

449 shortsighted.

$450 \quad$ Next steps

This study uncovered some important dimensions of residential preferences and use patterns 452 that can also be helpful in a variety of contexts. They could, for example, be useful both in the 453 context of strategies for engaging in physical activity and for planning and design solutions.

454 Engagement strategies. These strategies in environment-behavior studies are based on 455 accepting that satisfaction with some specific aspects of the environment can positively affect the 456 frequency of use of such spaces. For example, Duvall (2012) showed that "awareness plans" can 457 provide a strategy for engaging in specific aspects of the environment to encourage more 458 frequent use of outdoor spaces. Our findings point to some of the significant attributes of the 459 environment that specifically associate neighborhood satisfaction with the frequency of use of 460 public outdoor spaces. Since engagement-based strategies aim to positively affect environmental 461 satisfaction (Duval, 2013), focusing on the environmental attributes highlighted in our study may 462 be useful in improving engagement plans which ultimately result in more future outdoor 463 activities.

$464 \quad$ Planning and design solutions. The relatively fine-grained examination of four distinct 465 satisfaction measures and three distinct use measures in addition to specific barriers to use can 466 provide insights into appropriate planning and design considerations for new urban 
467 developments and redevelopment projects. This study highlights specific attributes of the

468 environment that contribute to higher level of satisfaction as well as some specific negative

469 attributes of the environment. Attention to these qualities could help planners and designers

470 create better places to live in urban areas according to residents' preferences. For instance, these

471 findings suggest that in order to improve use of outdoor spaces, we need to improve residents'

472 satisfaction with quality of public space by providing varieties of green spaces, opportunities for

473 socializing in outdoor spaces, increasing the amount of open spaces and improvements in their

474 overall appearance. This work also suggests that these improvements may not be effective as

475 long as there are perceived barriers to neighborhood use. Therefore, we also need to improve

476 maintenance, walkability and sense of community, while reducing safety concerns and physical

477 barriers.

478 While revealing many useful findings that contribute to the current literature, this study

479 raises several unanswered questions due to limitations and calls for further investigations. With

480 respect to the sample, there are potential biases related to both the low response rate of the

481 mailed survey and the use of on-site data collection. On-site participants are among residents

482 who are more likely to use neighborhood outdoor spaces in general, but that may or may not

483 mean that they are more satisfied with what is available to them. Reaching residents who are less

484 satisfied with their neighborhoods as well as those who use it less frequently would be both

485 useful and challenging. It is also important to reiterate that the distribution of data on perceived

486 barriers to neighborhood use was skewed towards the lower end of the scale, meaning that in

487 general, barriers played a minor role for study participants. More variability with respect to

488 perceived barriers could permit a better understanding of their role. Further, the interaction

489 effects of various perceived barriers and satisfaction with amount of green features on use of 
490 green/social spaces (Table 7), call for further study. As Table 8 shows, among the participants

491 who have the same level of satisfaction with amount of green features, those who perceive more

492 barriers in the neighborhood are likely to use green/social spaces more frequently. This is also

493 true in terms of the interaction effects of barriers and use of green/social spaces on neighborhood

494 comfort. Further investigation is required to consider other factors that may intervene in these

495 relationships.

496 In addition, the negative main effect of active engagement on satisfaction with amount of

497 affordances (Table 8) leaves room for further investigations. Our findings show that in a

498 perceived high-barrier situation, those who are more actively involved with the outdoor spaces

499 are less satisfied with the amount of activities afforded by the outdoor public spaces. One reason

500 might be because those who are more involved in outdoor activities are more aware of the

501 shortages in the neighborhood or would like to have more opportunities for outdoor activities.

502 The existing literature shows that teens and younger adults are more interested in using sports

503 fields and also people who have children prefer to have more playgrounds nearby (Hadavi,

504 Kaplan and Hunter, 2015). Further research on the role of demographics is needed to better

505 understand these findings.

$506 \quad$ Neighborhood satisfaction and use patterns are necessarily impacted by many factors. Future

507 research can further our understanding of how the physical attributes of the environment are

508 associated with each of these aspects of neighborhood satisfaction and use patterns, shedding

509 light on ways to create better livable spaces for residents through meeting their needs and

510 preferences. 


\section{Acknowledgements}

This research was supported by USDA-FS grant (no. 2013-32100-06099) as well as funds

from the University of Michigan's School of Natural Resources and Environment. We thank Dr. William C. Sullivan for providing constructive comments on earlier versions of this manuscript. 


\section{References}

Adriaanse, C. C. M. (2007). Measuring residential satisfaction: a residential environmental satisfaction scale (RESS). Journal of housing and the built environment, 22(3), 287-304.

Amérigo, M., \& Aragones, J. I. (1997). A theoretical and methodological approach to the study of residential satisfaction. Journal of environmental psychology, 17(1), 47-57.

Arnberger, A. \& Eder, R. (2012). The influence of green space on community attachment of urban and suburban residents. Urban Forestry and Urban Greening, 11(1):41-49. doi: http://dx.doi.org/10.1016/j.ufug.2011.11.003.

Ball, K., Bauman, A., Leslie, E., \& Owen, N. (2001). Perceived environmental aesthetics and convenience and company are associated with walking for exercise among Australian adults. Preventive Medicine, 33(5), 434-440. doi: http://dx.doi.org/10.1006/pmed.2001.0912

Basolo, V., \& Strong, D. (2002). Understanding the neighborhood: From residents' perceptions and needs to action. Housing Policy Debate, 13(1), 83-105. doi:

10.1080/10511482.2002.9521436

Bjork, J., Albin, M., Grahn, P., Jacobsson, H., Ardo, J., Wadbro, J., Ostergren, P-O, \& Skarback, E. (2008). Recreational values of the natural environment in relation to neighbourhood satisfaction, physical activity, obesity and wellbeing. Journal of Epidemiology \& Community Health, 62(4). doi::10.1136/jech.2007.062414

Bonaiuto, M., Aiello, A., Perugini, M., Bonnes, M., \& Ercolani, A. P. (1999). Multidimensional perception of residential environment quality and neighborhood attachment in the urban environment. Journal of Environmental Psychology, 19, 331352.

Burby, R. J., \& Rohe, W. M. (1989). Deconcentration of public housing effects on residents' satisfaction with their living environments and their fear of crime. Urban Affairs Review, 25(1), 117-141.

Cook, C. C. (1988). Components of neighborhood satisfaction responses from urban and suburban single-parent women. Environment and Behavior, 20(2), 115-149. doi: $10.1177 / 0013916588202001$

de Jong, K., Albin, M., Skarback, E., Grahn, P., \& Bjork, J. (2012). Perceived green qualities were associated with neighborhood satisfaction, physical activity, and general health: Results from a cross-sectional study in suburban and rural Scania, southern Sweden. Health and Place, 18(6), 1374-1380. doi: 10.1016/j.healthplace.2012.07.001

Duvall, J. (2012). A comparison of engagement strategies for encouraging outdoor walking. Journal of Physical Activity and Health, 9(1), 62-70.

Duvall, J. (2013). Using engagement-based strategies to alter perceptions of the walking environment. Environment and Behavior, 45(3), 303-322. doi: 10.1177/0013916511423808

Ellis, C. D., Lee, S. W., \& Kweon, B. S. (2006). Retail land use, neighborhood satisfaction and the urban forest: an investigation into the moderating and mediating effects of trees and shrubs. Landscape and Urban Planning, 74(1), 70-78. doi: 10.1016/j.landurbplan.2004.10.004

Fernandez, R. M., \& Kulik, J. C. (1981). A multilevel model of life satisfaction: Effects of individual characteristics and neighborhood composition. American Sociological Review, 46(6), 840. doi: 10.2307/2095082 
Fornara, F., Bonaiuto, M., \& Bonnes, M. (2010). Cross-validation of abbreviated perceived residential environment quality (PREQ) and neighborhood attachment (NA) indicators. Environment and Behavior, 42(2), 171-196.

Francescato, G. (2002). Residential satisfaction research: The case for and against. In G. Aragones, G. Francescato \& T. Garling (Eds.), Residential environments: Choice, satisfaction, and behavior (pp. 15-34). Wesport, CT: Bergin \& Garvey.

Galster, G. C., \& Hesser, G. W. (1981). Residential satisfaction: Compositional and contextual correlates. Environment and Behavior, 13(6), 735-758. doi: 10.1177/0013916581136006

Giles-Corti, B., Broomhall, M. H., Knuiman, M., Collins, C., Douglas, K., Ng, K., . . Donovan, R. J. (2005). Increasing walking: How important is distance to, attractiveness, and size of public open space? American Journal of Preventive Medicine, 28(2, Supplement 2), 169176. doi: http://dx.doi.org/10.1016/j.amepre.2004.10.018

Gruber, K., \& Shelton, G. (1987). Assessment of neighborhood satisfaction by residents of three housing types. Social Indicators Research, 19(3), 303-315. doi: 10.1007/bf00300363

Hadavi, S. (2015). "Nearby nature and mental wellbeing: A designer's perspective." Doctoral Dissertation. University of Michigan, 54-57.

Hadavi, S., Kaplan, R., \& Hunter, M. R. (2015). Environmental affordances: A practical approach for design of nearby outdoor settings in urban residential areas. Landscape and Urban Planning 134 (0):19-32. doi: http://dx.doi.org/10.1016/j.landurbplan.2014.10.001.

Humpel, N., Marshall, A., Leslie, E., Bauman, A., \& Owen, N. (2004). Changes in neighborhood walking are related to changes in perceptions of environmental attributes. Annals of Behavioral Medicine, 27(1), 60-67. doi: 10.1207/s15324796abm2701_8

Hur, M., \& Morrow-Jones, H. (2008). Factors that influence residents' satisfaction with neighborhoods. Environment and Behavior, 40(5), 619-635. doi: 10.1177/0013916507307483

Hur, M., \& Nasar, J. L. (2014). Physical upkeep, perceived upkeep, fear of crime and neighborhood satisfaction. Journal of Environmental Psychology, 38(0), 186-194. doi: http://dx.doi.org/10.1016/j.jenvp.2014.02.001

Hur, M., Nasar, J. L., \& Chun, B. (2010). Neighborhood satisfaction, physical and perceived naturalness and openness. Journal of Environmental Psychology, 30(1), 52-59.

Kaplan, R. (2001). The nature of the view from home - Psychological benefits. Environment and Behavior, 33(4), 507-542. doi: 10.1177/00139160121973115

Kaplan, R., \& Kaplan, S. (1989). The experience of nature: A psychological perspective. New York: Cambridge University Press (Republished by Ann Arbor, MI: Ulrich's, 1995).

Kaplan, R., Kaplan, S., \& Ryan, R. L. (1998). With people in mind: Design and management of everyday nature. Washington, D.C.: Island Press.

Kaplan, S., \& Kaplan, R. (1982). Cognition and environment: Functioning in an uncertain world. New York: Praeger (Republished by Ann Arbor, MI: Ulrich's, 1989).

Kearney, A. R. (2006). Residential development patterns and neighborhood satisfaction Impacts of density and nearby nature. Environment and Behavior, 38(1), 112-139. doi: 10.1177/0013916505277607

Kweon, B. S., Ellis, C. D., Leiva, P. I., \& Rogers, G. O. (2010). Landscape components, land use, and neighborhood satisfaction. Environment and Planning B-Planning \& Design, 37(3), 500-517. doi: 10.1068/b35059

Lee, B. A. (1981). The urban unease revisited: Perceptions of local safety and neighborhood satisfaction among metropolitan residents. Social Science Quarterly, 62(4), 611-629. 
Lee, S. W., Ellis, C. D., Kweon, B. S., \& Hong, S. K. (2008). Relationship between landscape structure and neighborhood satisfaction in urbanized areas. Landscape and Urban Planning, 85(1), 60-70. doi: 10.1016/j.landurbplan.2007.09.013

Lovejoy, K., Handy, S., \& Mokhtarian, P. (2010). Neighborhood satisfaction in suburban versus traditional environments: An evaluation of contributing characteristics in eight California neighborhoods. Landscape and Urban Planning, 97(1), 37-48. doi: http://dx.doi.org/10.1016/j.landurbplan.2010.04.010

Macintyre, S., Macdonald, L., \& Ellaway, A. (2008). Lack of agreement between measured and self-reported distance from public green parks in Glasgow, Scotland. International Journal of Behavioral Nutrition and Physical Activity, 5. doi: 2610.1186/1479-5868-5-26

Parkes, A., Kearns, A., \& Atkinson, R. (2002). What makes people dissatisfied with their neighbourhoods? Urban Studies, 39(13), 2413-2438. doi: 10.1080/0042098022000027031

Rohe, W. M., Van Zandt, S., \& McCarthy, G. (2013). The social benefits and costs of home ownership: A critical assessment of the research. In J. R. Tighe \& E. J. Mueller (Eds.), The affordable housing reader (pp. 196-213). New York: Routledge.

Sallis, J. F., Saelens, B. E., Frank, L. D., Conway, T. L., Slymen, D. J., Cain, K. L., . . Kerr, J. (2009). Neighborhood built environment and income: Examining multiple health outcomes. Social Science \& Medicine, 68(7), 1285-1293. doi: http://dx.doi.org/10.1016/j.socscimed.2009.01.017

Shackleton, C. M., \& Blair, A. (2013). Perceptions and use of public green space is influenced by its relative abundance in two small towns in South Africa. Landscape and Urban Planning, 113, 104-112. doi: 10.1016/j.landurbplan.2013.01.011

Sirgy, M. J., \& Cornwell, T. (2002). How neighborhood features affect quality of life. Social Indicators Research, 59(1), 79-114. doi: 10.1023/a:1016021108513

Tinsley, H. E. A., Tinsley, D. J., \& Croskeys, C. E. (2002). Park usage, social milieu, and psychosocial benefits of park use reported by older urban park users from four ethnic groups. Leisure Sciences, 24(2), 199-218. doi: 10.1080/01490400252900158

Ward Thompson, C. (2011). Linking landscape and health: The recurring theme. Landscape and Urban Planning, 99(3-4), 187-195. doi: http://dx.doi.org/10.1016/j.landurbplan.2010.10.006

Ward Thompson, C. (2013). Activity, exercise and the planning and design of outdoor spaces. Journal of Environmental Psychology, 34(0), 79-96. doi: http://dx.doi.org/10.1016/j.jenvp.2013.01.003

Ward Thompson, C., \& Aspinall, P. A. (2011). Natural Environments and their Impact on Activity, Health, and Quality of Life. Applied Psychology: Health and Well-Being, 3(3), 230-260. doi:10.1111/j.1758-0854.2011.01053.x

Wright Wendel, H. E., Zarger, R. K., \& Mihelcic, J. R. (2012). Accessibility and usability: Green space preferences, perceptions, and barriers in a rapidly urbanizing city in Latin America. Landscape and Urban Planning, 107(3), 272-282. doi: http://dx.doi.org/10.1016/j.landurbplan.2012.06.003 


\section{List of Figures:}

Fig.1 Study site within Chicago, Illinois including parts of four community areas with various types and sizes of green spaces

Fig.2 The associations between aspects of neighborhood satisfaction, forms of use and barriers

Fig.3 The complex interaction effects of barriers to neighborhood use in the association between neighborhood satisfaction and use 


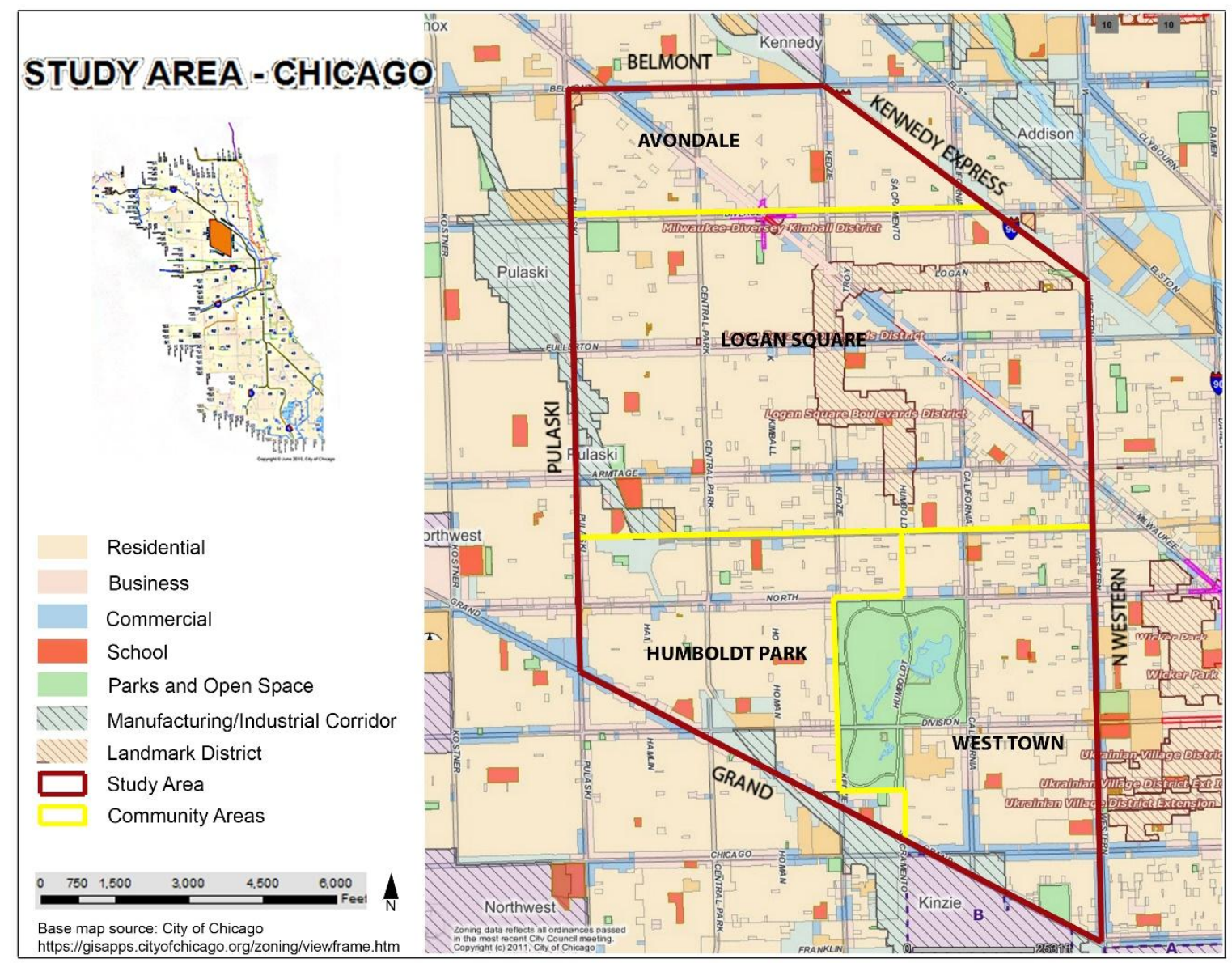

Fig.1 Study site within Chicago, Illinois including parts of four community areas with various types and sizes of green spaces 


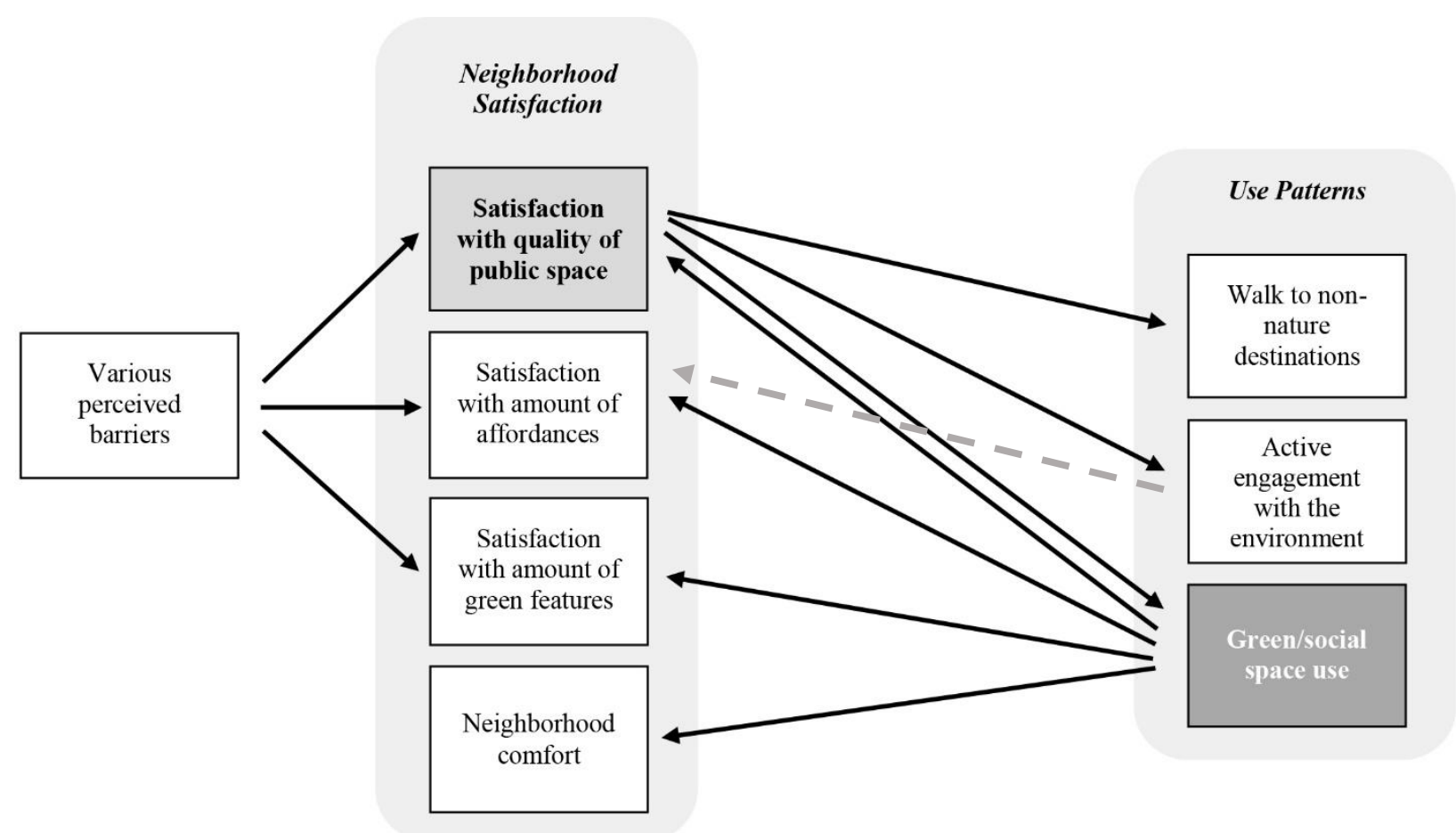

Fig. 2 The associations between aspects of neighborhood satisfaction, forms of use and barriers based on main effects. The dashed arrow shows the negative association. 


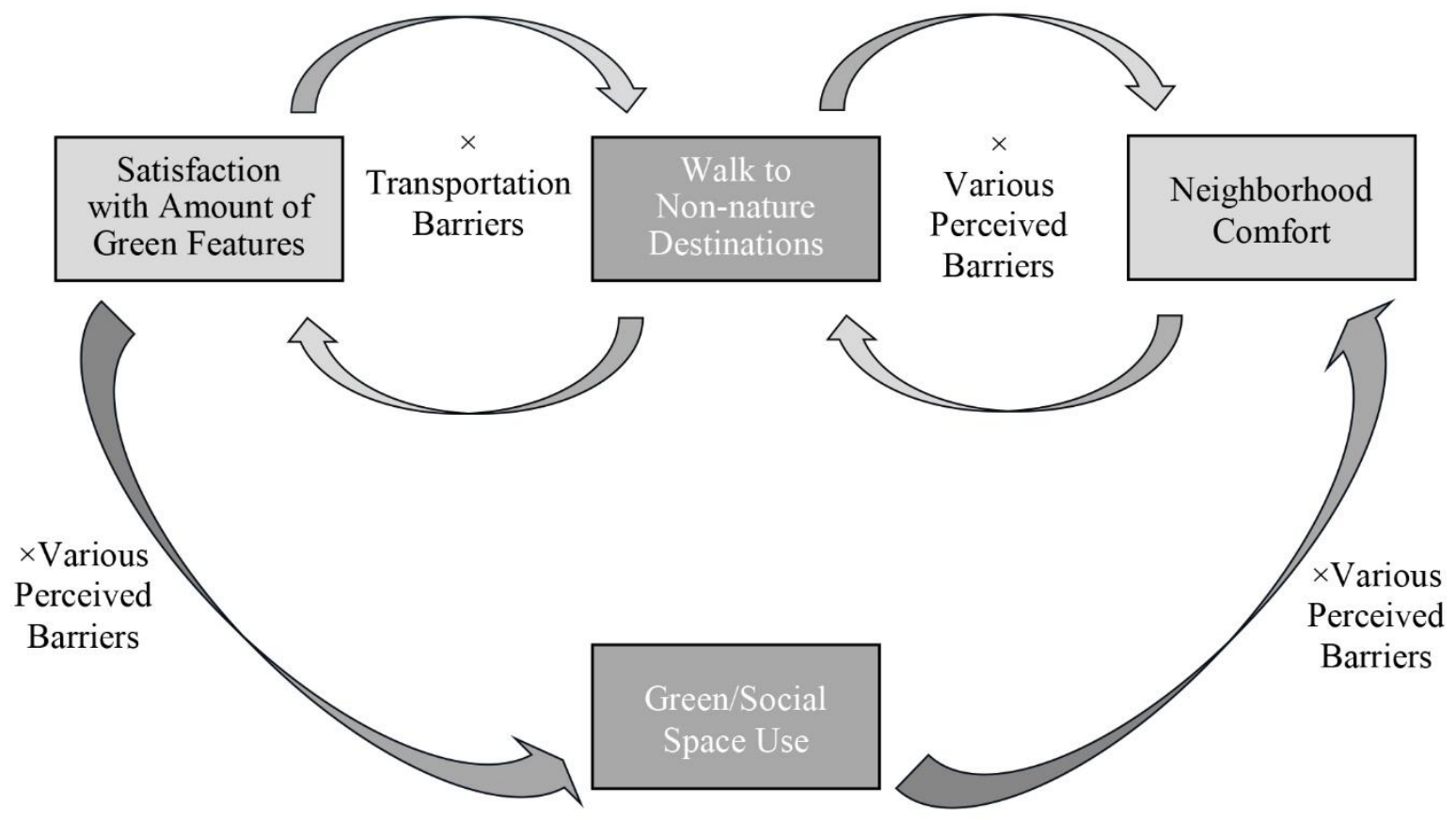

Fig.3 The interaction effects of barriers to neighborhood use in the association between neighborhood satisfaction and use, based on the results presented in Tables 7 and 8. 


\section{List of Tables:}

Table 1 Survey questions on neighborhood satisfaction, use patterns and barriers to use Table 2. Sample characteristics

Table 3. Neighborhood Satisfaction factors and factor loadings

Table 4. Neighborhood Use Patterns factors and factor loadings

Table 5. Barriers to Neighborhood Use factors

Table 6. Correlations between components of neighborhood satisfaction and use pattern (Pearson Correlation, 2-tailed significance test)

Table 7. The effects of neighborhood satisfaction measures on three forms of use while considering the interaction effects of perceived barriers to use ${ }^{*}$

Table 8 . The effects of use patterns measures on four aspects of neighborhood satisfaction while considering the interaction effects of perceived barriers to use ${ }^{*}$ 
Table 1 Survey questions on neighborhood satisfaction, use patterns and barriers to use Neighborhood satisfaction

Thinking about your nearby environment, how do you feel about the amount of the following?

Public green spaces

Large trees

Shrubs and bushes

Lawns

Flower beds

Vegetable gardens

Sitting areas

Outdoor gathering/picnic areas

Children's play areas

Opportunities for positive interactions with neighbors

scale: $1=$ much too little, $2=$ too little, $3=$ about right, $4=$ too much, $5=$ much too much

How satisfied are you with the nearby neighborhood in terms of these?

Overall appearance

Amount of open space

Variety of the green spaces

Street lighting

Farmers market

Sense of community

Peacefulness

Safety for walking during the day

Safety for walking at night

Opportunities for outdoor community/friends gathering

scale: $1=$ not at all satisfied, $2=$ a little, $3=$ somewhat, $4=$ quite a bit, $5=$ very satisfied

\begin{tabular}{|c|c|}
\hline \multicolumn{2}{|l|}{ Use patterns } \\
\hline $\begin{array}{l}\text { How often do you walk within your } \\
\text { neighborhood? }\end{array}$ & $\begin{array}{l}\text { For pleasure } \\
\text { To visit someone } \\
\text { To visit a green space } \\
\text { To walk a dog } \\
\text { To make a purchase } \\
\text { To get to a metro/bus stop } \\
\text { To go to recreational areas/clubhouse/coffee } \\
\text { shop/restaurant } \\
\text { To reach a specific destination (e.g., church, } \\
\text { school, work) }\end{array}$ \\
\hline $\begin{array}{l}\text { How often do you visit/use each of the } \\
\text { following in your neighborhood? }\end{array}$ & $\begin{array}{l}\text { Community garden } \\
\text { Boulevard seating areas } \\
\text { Park-like square } \\
\text { Playlot/playground } \\
\text { Sports fields } \\
\text { Park with large trees } \\
\text { Outdoor gathering/picnic areas }\end{array}$ \\
\hline $\begin{array}{l}\text { How often do you do each of these in your } \\
\text { neighborhood? }\end{array}$ & $\begin{array}{l}\text { Outdoor sitting and watching } \\
\text { Running } \\
\text { Biking } \\
\text { Outdoor community/friends gathering } \\
\text { Picnicking } \\
\text { Resting on the lawn } \\
\text { Garden at a community garden }\end{array}$ \\
\hline Barriers to neighborhood use & \\
\hline $\begin{array}{l}\text { How much do each of these discourage you } \\
\text { from pursuing activities in your } \\
\text { neighborhood? }\end{array}$ & $\begin{array}{l}\text { Traffic } \\
\text { Major roads } \\
\text { Distance } \\
\text { Safety concerns } \\
\text { Unpleasant open spaces } \\
\text { Low maintenance } \\
\text { Fences } \\
\text { Lack of information about availability } \\
\text { Lack of walkable sidewalks } \\
\text { Lack of sense of community }\end{array}$ \\
\hline
\end{tabular}


Table 2. Sample characteristics

\begin{tabular}{|c|c|}
\hline & Study sample (\%) \\
\hline \multicolumn{2}{|l|}{ Gender } \\
\hline Female & 59.6 \\
\hline Male & 40.4 \\
\hline \multicolumn{2}{|l|}{ Marital status } \\
\hline \multirow{2}{*}{$\begin{array}{l}\text { Married or with partner } \\
\text { single }\end{array}$} & 52.5 \\
\hline & 46.3 \\
\hline \multicolumn{2}{|l|}{ Children } \\
\hline No & 71.7 \\
\hline Yes & 27.2 \\
\hline \multicolumn{2}{|l|}{ Education level } \\
\hline Less than high school & .9 \\
\hline High school & 2.1 \\
\hline Technical degree & 1.6 \\
\hline Some college & 13.1 \\
\hline College degree & 45.6 \\
\hline Post-graduate degree & 35.9 \\
\hline \multicolumn{2}{|l|}{ Work status } \\
\hline Work full-time & 69.1 \\
\hline Work part-time & 15.0 \\
\hline Student & 10.8 \\
\hline Homemaker & 7.8 \\
\hline Retired & 3.9 \\
\hline Volunteer work & 4.4 \\
\hline \multicolumn{2}{|l|}{ Total household income (\$) } \\
\hline$<25,000$ & 15.2 \\
\hline $25,000-34,999$ & 8.6 \\
\hline $35,000-49,999$ & 15.5 \\
\hline $50,000-74,999$ & 19.5 \\
\hline $75,000-100,000$ & 16.7 \\
\hline $100,000+$ & 24.5 \\
\hline \multicolumn{2}{|c|}{ Amount of time to get to work/school (Minutes) } \\
\hline$<15$ & 10 \\
\hline $15-30$ & 40 \\
\hline $30-45$ & 20 \\
\hline $45+$ & 15 \\
\hline N/A & 15 \\
\hline \multicolumn{2}{|l|}{ How to get to work/school } \\
\hline Walk & 15.4 \\
\hline Car & 39.6 \\
\hline Bus & 18.0 \\
\hline Train & 36.2 \\
\hline Bike & 22.6 \\
\hline N/A & 11.8 \\
\hline \multicolumn{2}{|c|}{ Amount of time living in the neighborhood (Years) } \\
\hline$<1$ & 13.6 \\
\hline $1-2$ & 17.3 \\
\hline $3-5$ & 27.0 \\
\hline $6-10$ & 21.4 \\
\hline $10+$ & 9.9 \\
\hline
\end{tabular}


Table 3. Neighborhood Satisfaction factors and factor loadings

\begin{tabular}{|c|c|c|c|c|}
\hline Item (Mean) & $\begin{array}{c}\mathrm{F} 1^{*} \\
\text { Amount of } \\
\text { Affordances }\end{array}$ & $\begin{array}{c}\mathrm{F} 2^{*} \\
\text { Amount of } \\
\text { Green } \\
\text { Features }\end{array}$ & $\begin{array}{c}\text { F3 } \\
\text { Quality of } \\
\text { Public } \\
\text { Space }\end{array}$ & $\begin{array}{c}\mathrm{F} 4 \\
\text { Neighborhood } \\
\text { Comfort }\end{array}$ \\
\hline
\end{tabular}

Thinking about your nearby environment, how do

you feel about the amount of the following?

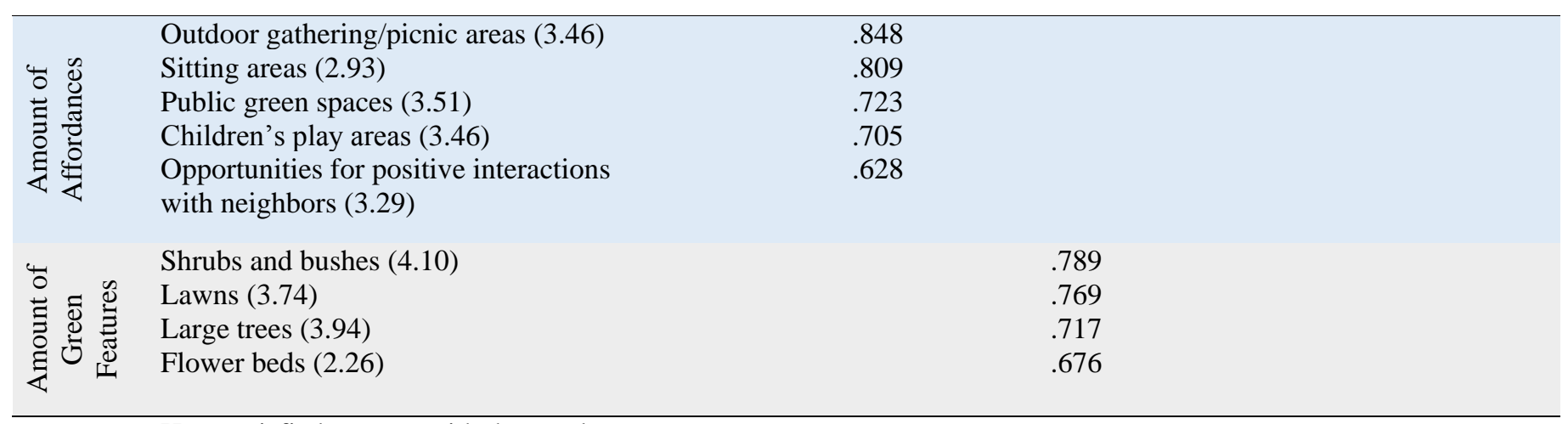

How satisfied are you with the nearby neighborhood in terms of these?

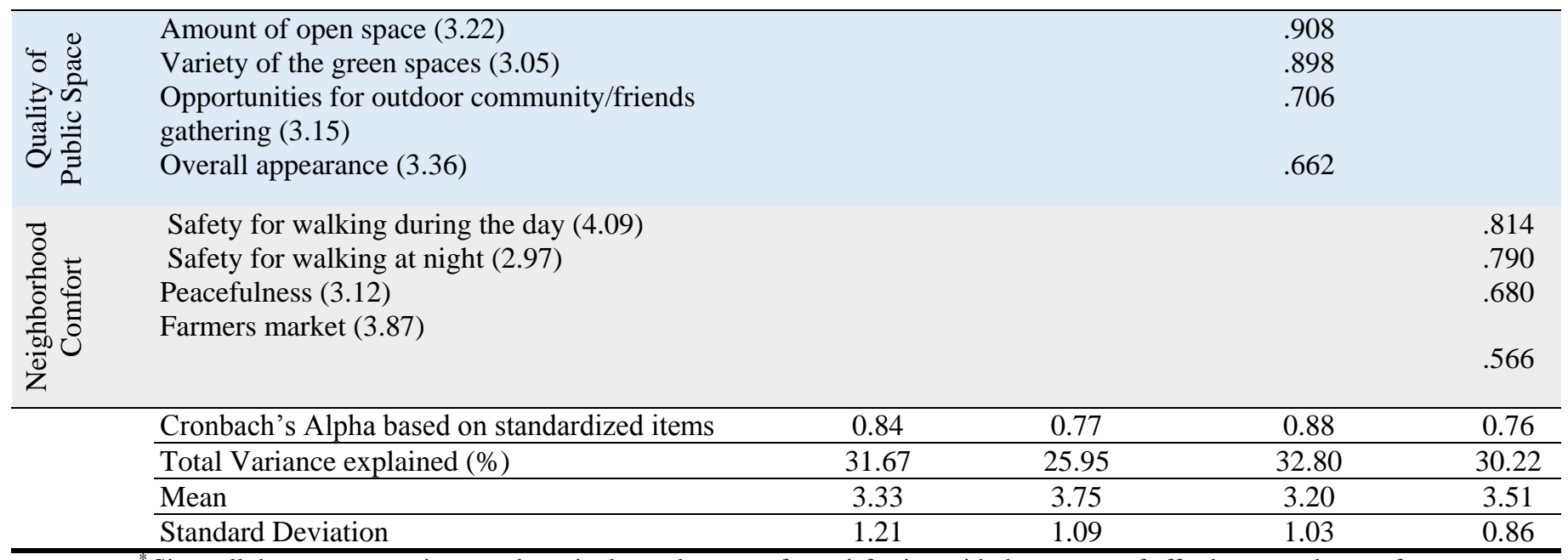

Since all the survey questions used a unipolar scale except for satisfaction with the amount of affordances and green features, for these factors the bipolar scale was recoded as a unipolar scale going from $1=$ much too much or much too little to $5=$ about right. 
Table 4. Neighborhood Use Patterns factors and factor loadings

\begin{tabular}{|c|c|c|c|c|}
\hline & Item (Mean) & $\begin{array}{c}\text { F1 } \\
\text { Green/Social } \\
\text { Space Use }\end{array}$ & $\begin{array}{c}\mathrm{F} 2 \\
\text { Active } \\
\text { Engagement }\end{array}$ & $\begin{array}{c}\mathrm{F} 3 \\
\text { Walk to Non- } \\
\text { nature } \\
\text { Destinations }\end{array}$ \\
\hline \multirow{10}{*}{ 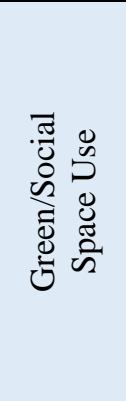 } & Park-like square (3.25) & .807 & & \\
\hline & Outdoor gathering/picnic areas (2.90) & .752 & & \\
\hline & Park with large trees (3.53) & .750 & & \\
\hline & Resting on the lawn (2.72) & .726 & & \\
\hline & To visit a green space (3.42) & .723 & & \\
\hline & Boulevard seating areas (2.66) & 687 & & \\
\hline & Outdoor community/friends gathering (2.99) & 680 & & \\
\hline & Outdoor sitting and watching (3.25) & .673 & & \\
\hline & Picnicking (2.23) & .644 & & \\
\hline & Walk for pleasure (3.72) & 625 & & \\
\hline \multirow{4}{*}{ 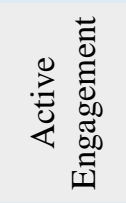 } & Garden at a community garden (1.56) & & .841 & \\
\hline & Community garden (1.76) & & .818 & \\
\hline & Playlot/playground (2.33) & & .632 & \\
\hline & Sports fields (1.82) & & .570 & \\
\hline \multirow{9}{*}{ 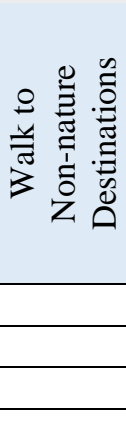 } & Walk to make a purchase (4.17) & & & .715 \\
\hline & Walk to a metro/bus stop (4.03) & & & .711 \\
\hline & $\begin{array}{l}\text { Walk to a specific destination (e.g., church, school, work) } \\
\text { (3.79) }\end{array}$ & & & .661 \\
\hline & $\begin{array}{l}\text { Walk to recreational areas/clubhouse/coffee shop/restaurant } \\
(4.11)\end{array}$ & & & 639 \\
\hline & Walk to visit someone (3.53) & & & .566 \\
\hline & Cronbach's Alpha based on standardized items & 0.91 & 0.76 & 0.76 \\
\hline & Total Variance explained (\%) & 26.3 & 11.9 & 11.8 \\
\hline & Mean & 3.08 & 1.87 & 3.92 \\
\hline & Standard Deviation & 0.98 & 0.94 & 0.87 \\
\hline
\end{tabular}


Table 5. Barriers to Neighborhood Use factors

\begin{tabular}{llcc}
\hline & Item (Mean) & $\begin{array}{c}\text { F1 } \\
\text { Various } \\
\text { Perceived } \\
\text { Barriers }\end{array}$ & $\begin{array}{c}\text { Transportation } \\
\text { Barriers }\end{array}$ \\
\hline & Low maintenance (2.23) & .738 \\
& Unpleasant open space (2.18) & .728 & \\
& Lack of information about availability (2.35) & .717 & \\
Various Perceived & Lack of walkable sidewalks (1.55) & .695 & \\
Barriers & Fences (1.85) & .682 & \\
& Lack of sense of community (2.11) & .668 & \\
& Safety concerns (2.36) & .607 & .940 \\
& Major roads (2.33) & & .916 \\
Transportation Barriers & Traffic (2.36) & .524 \\
\hline & Distance (2.31) & 0.81 \\
\hline Cronbach's Alpha based on standardized items & 0.85 & 23.5 \\
\hline \multicolumn{2}{l}{ Total Variance explained (\%) } & 36.0 & 2.34 \\
\hline Mean & & 2.09 & 1.10 \\
\hline Standard Deviation & 0.86 & \\
\hline
\end{tabular}


Table 6. Correlations between components of neighborhood satisfaction and use pattern (Pearson Correlation, 2-tailed significance test)

\begin{tabular}{|c|c|c|c|c|c|c|c|c|c|c|}
\hline & \multicolumn{4}{|c|}{ Neighborhood satisfaction } & \multicolumn{3}{|c|}{ Neighborhood use patterns } & \multicolumn{2}{|c|}{ Barriers to Neighborhood use } \\
\hline & & $\begin{array}{l}\text { Amount of } \\
\text { Affordances }\end{array}$ & $\begin{array}{l}\text { Amount } \\
\text { of Green } \\
\text { Features } \\
\end{array}$ & $\begin{array}{l}\text { Quality of } \\
\text { Public } \\
\text { Space } \\
\end{array}$ & $\begin{array}{l}\text { Neighborhood } \\
\text { Comfort }\end{array}$ & $\begin{array}{l}\text { Green/Social } \\
\text { Space Use }\end{array}$ & $\begin{array}{l}\text { Active } \\
\text { engagement }\end{array}$ & $\begin{array}{l}\text { Walk to Non- } \\
\text { nature } \\
\text { Destinations }\end{array}$ & $\begin{array}{l}\text { Various } \\
\text { Perceived } \\
\text { Barriers } \\
\end{array}$ & $\begin{array}{l}\text { Transportation } \\
\text { Barriers }\end{array}$ \\
\hline. & $\begin{array}{l}\text { Amount of } \\
\text { Affordances }\end{array}$ & 1 & & & & & & & & \\
\hline$\stackrel{\pi}{\mathscr{n}}$ & $\begin{array}{l}\text { Amount of } \\
\text { Green Features }\end{array}$ & $.537^{* *}$ & 1 & & & & & & & \\
\hline 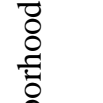 & $\begin{array}{l}\text { Quality of } \\
\text { Public Space }\end{array}$ & $.565^{* *}$ & $.278^{* *}$ & 1 & & & & & & \\
\hline $\begin{array}{l}\frac{\vec{c}}{.00} \\
\frac{\vec{v}}{\mathrm{z}}\end{array}$ & $\begin{array}{l}\text { Neighborhood } \\
\text { Comfort }\end{array}$ & $.292^{* *}$ & $.196^{* *}$ & $.618^{* *}$ & 1 & & & & & \\
\hline $\begin{array}{ll}\infty \\
z\end{array}$ & $\begin{array}{l}\text { Green/Social } \\
\text { Space Use }\end{array}$ & $.365^{* *}$ & $.141^{* *}$ & $.633^{* *}$ & $.386^{* *}$ & 1 & & & & \\
\hline 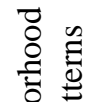 & $\begin{array}{l}\text { Active } \\
\text { Engagement }\end{array}$ & .058 & .013 & $.263^{* *}$ & .082 & $.480^{* *}$ & 1 & & & \\
\hline 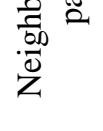 & $\begin{array}{l}\text { Walk to Non- } \\
\text { nature } \\
\text { Destinations }\end{array}$ & $.178^{* *}$ & $.096^{*}$ & $.355^{* *}$ & $.344^{* *}$ & $.429^{* *}$ & $.132^{* *}$ & 1 & & \\
\hline 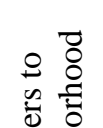 & $\begin{array}{l}\text { Various } \\
\text { Perceived } \\
\text { Barriers }\end{array}$ & $-.335^{* *}$ & $-.175^{* *}$ & $-.398^{* *}$ & $-.366^{* *}$ & $-.227^{* *}$ & -.044 & $-.120^{*}$ & 1 & \\
\hline 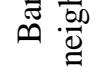 & $\begin{array}{l}\text { Transportation } \\
\text { Barriers }\end{array}$ & $-.225^{* *}$ & $-.162^{* *}$ & $-.308^{* * *}$ & $-.207^{* *}$ & $-.134^{* *}$ & .021 & -.094 & $.393^{* *}$ & 1 \\
\hline
\end{tabular}

. Correlation is significant at the 0.01 level (2-tailed)

*. Correlation is significant at the 0.05 level (2-tailed). 
Table 7. The effects of neighborhood satisfaction measures on three forms of use while considering the interaction effects of perceived barriers to use ${ }^{*}$

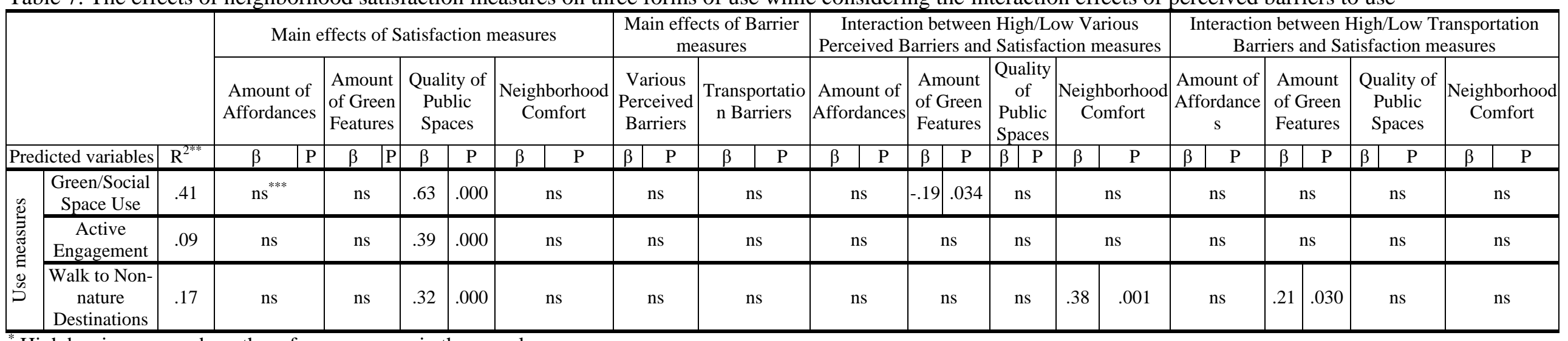

${ }^{*}$ High barriers are made as the reference groups in these analyses

Adjusted R Squared

*** Statistically not significant 
Table 8. The effects of use patterns measures on four aspects of neighborhood satisfaction while considering the interaction effects of perceived barriers to use ${ }^{*}$

\begin{tabular}{|c|c|c|c|c|c|c|c|c|c|c|c|c|c|c|c|c|c|c|c|c|c|c|c|}
\hline & \multicolumn{6}{|c|}{ Main effects of Use measures } & \multicolumn{4}{|c|}{$\begin{array}{c}\text { Main effects of } \\
\text { categorized } \\
\text { Barrier } \\
\text { measures }\end{array}$} & \multicolumn{5}{|c|}{$\begin{array}{c}\text { Interaction between } \\
\text { High/Low Various } \\
\text { Perceived Barriers and } \\
\text { Use measures }\end{array}$} & \multicolumn{6}{|c|}{$\begin{array}{c}\text { Interaction between } \\
\text { High/Low Transportation } \\
\text { Barriers and Use measures }\end{array}$} \\
\hline & & & \multicolumn{2}{|c|}{$\begin{array}{c}\text { Green/Soci } \\
\text { al Space } \\
\text { Use }\end{array}$} & \multicolumn{2}{|c|}{$\begin{array}{l}\text { Active } \\
\text { Engage } \\
\text { ment }\end{array}$} & \multicolumn{2}{|c|}{\begin{tabular}{|c} 
Walk to \\
Non- \\
nature \\
Destinati \\
ons \\
\end{tabular}} & \multicolumn{2}{|c|}{$\begin{array}{c}\text { Various } \\
\text { Perceiv } \\
\text { ed } \\
\text { Barrier } \\
\mathrm{s}\end{array}$} & \multicolumn{2}{|c|}{\begin{tabular}{|c} 
Transp \\
ortatio \\
$n$ \\
Barrie \\
rs \\
\end{tabular}} & \multicolumn{2}{|c|}{$\begin{array}{c}\text { Green/So } \\
\text { cial } \\
\text { Space } \\
\text { Use }\end{array}$} & $\begin{array}{c}\text { Activ } \\
\mathrm{e} \\
\text { Enga } \\
\text { geme } \\
\mathrm{nt}\end{array}$ & \multicolumn{2}{|c|}{$\begin{array}{c}\text { Walk to } \\
\text { Non- } \\
\text { nature } \\
\text { Destinat } \\
\text { ions }\end{array}$} & \multicolumn{2}{|c|}{$\begin{array}{l}\text { Green/S } \\
\text { ocial } \\
\text { Space } \\
\text { Use }\end{array}$} & \multicolumn{2}{|c|}{$\begin{array}{l}\text { Active } \\
\text { Engage } \\
\text { ment }\end{array}$} & \multicolumn{2}{|c|}{$\begin{array}{c}\text { Walk to } \\
\text { Non- } \\
\text { nature } \\
\text { Destinati } \\
\text { ons }\end{array}$} \\
\hline & $\begin{array}{l}\text { Predicted } \\
\text { variables }\end{array}$ & $\mathrm{R}^{2^{* *}}$ & $\beta$ & $\mathrm{P}$ & $\beta$ & $\mathrm{P}$ & $\beta$ & $\mathrm{P}$ & $\beta$ & $\mathrm{P}$ & $\beta$ & $\mathrm{P}$ & $\beta$ & $\mathrm{P}$ & \begin{tabular}{l|l}
$\beta$ & $\mathrm{P}$ \\
\end{tabular} & $\beta$ & $\mathrm{P}$ & $\beta$ & $\mathrm{P}$ & $\beta$ & $\mathrm{P}$ & $\beta$ & $\mathrm{P}$ \\
\hline \multirow{4}{*}{ 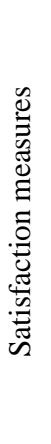 } & $\begin{array}{l}\text { Amount of } \\
\text { Affordance } \\
\mathrm{S}\end{array}$ & .22 & .66 & .000 & -.27 & $\begin{array}{l}.0 \\
15\end{array}$ & $\mathrm{n}$ & & $\begin{array}{c}1.6 \\
5\end{array}$ & $\begin{array}{c}.00 \\
2\end{array}$ & $\mathrm{~ns}$ & is & & ns & ns & & ns & $\mathrm{ns}$ & & $\mathrm{ns}$ & & \multicolumn{2}{|c|}{ ns } \\
\hline & \begin{tabular}{|l|} 
Amount of \\
Green \\
Features \\
\end{tabular} & .06 & .33 & .002 & \multicolumn{2}{|c|}{$\mathrm{ns}^{* * *}$} & \multicolumn{2}{|c|}{ ns } & $\begin{array}{c}1.4 \\
3\end{array}$ & $\begin{array}{l}.0 \\
08\end{array}$ & $\mathrm{n}$ & is & \multicolumn{2}{|c|}{$\mathrm{ns}$} & ns & \multicolumn{2}{|c|}{$\mathrm{ns}$} & $\mathrm{ns}$ & & \multicolumn{2}{|c|}{ ns } & .30 & $\begin{array}{c}.03 \\
3\end{array}$ \\
\hline & \begin{tabular}{|l|} 
Quality of \\
Public \\
Spaces \\
\end{tabular} & .49 & .72 & .000 & \multicolumn{2}{|c|}{ ns } & \multicolumn{2}{|c|}{ ns } & .88 & $\begin{array}{l}.0 \\
21\end{array}$ & \multicolumn{2}{|c|}{ ns } & \multicolumn{2}{|c|}{ ns } & ns & \multicolumn{2}{|c|}{$\mathrm{ns}$} & $\mathrm{ns}$ & & \multicolumn{2}{|c|}{ ns } & \multicolumn{2}{|c|}{$\mathrm{ns}$} \\
\hline & \begin{tabular}{|l|} 
Neighborh \\
ood \\
Comfort
\end{tabular} & .28 & .37 & .000 & \multicolumn{2}{|c|}{ ns } & \multicolumn{2}{|c|}{ ns } & \multicolumn{2}{|c|}{$\mathrm{ns}$} & \multicolumn{2}{|c|}{ ns } & $\begin{array}{c}- \\
.23\end{array}$ & .030 & ns & .32 & $\begin{array}{c}.00 \\
1\end{array}$ & $\mathrm{~ns}$ & & $\mathrm{~ns}$ & & $\mathrm{n}$ & \\
\hline
\end{tabular}

"High barriers are made as the reference groups in these analyses

*** Adjusted R Squared

**** Statistically not significant

${ }^{1}$ Census data: http://www.socialexplorer.com/tables/ACS2009_5yr/R10591609; Census tract boundaries: http://www.census.gov/geo/www/tiger/

${ }^{2}$ Source: Landuse inventory 2005; http://www.cmap.illinois.gov/land-use-inventory

${ }^{3}$ Source: https://data.cityofchicago.org/browse?tags=gis 